\title{
Calculation Technique of A Moisture-binding Energy at Freezing of Milk Products
}

\section{Azret Utebayevich Shingisov ${ }^{1}$, Bauyrzhan Geitzhanovich Myrkhalykov ${ }^{2}$ and Saule Azhikhanovna Mussayeva ${ }^{1}$}

\author{
Azret Utebayevich Shingisov, M. Auezov South Kazakhstan \\ State University, 160012, Shymkent city, Kazakhstan.
}

http://dx.doi.org/10.13005/bbra/2023

(Received: 10 November 2015; accepted: 04 January 2016)

\begin{abstract}
A sheep milk from different regions of Kazakhstan was a subject of the research. The research established that beginning of the milk's water-ice phase transition, i.e. cryoscopic temperature for a sheep milk of South Kazakhstan oblast is $-1.1^{\circ} \mathrm{C}$, and for a sheep milk of Almaty oblast is $-1.2^{\circ} \mathrm{C}$. The research proved that at the freezing of the sheep milk from South Kazakhstan oblast in the interval cryoscopic temperature to $10^{\circ} \mathrm{C}$, the frozen out moisture content in the sheep milk increases from $0 \%$ to $87 \%$. Respectively the frozen out moisture content in the sheep milk from Almaty oblast increases from $0 \%$ to $88 \%$. A smooth and graded transition of the rest loosely bound moisture to ice was noted at the further temperature decrease from $-10^{\circ} \mathrm{C}$ to $-20^{\circ} \mathrm{C}$ and below. The research established that $b$ coefficient value, considering tightly bound moisture in the sheep milk from South Kazakhstan oblast is $b=\mathbf{0 . 0 7 5 2}$, and in the sheep milk from Almaty oblast it is $\mathbf{b}=\mathbf{0 . 0 8 0 5}$. Comparison of numeric values between theoretically calculated moisturebinding energy and experimental data at the freezing of the sheep milk samples shows that the difference is no more than $2.7 \%$. This proves justification of conditions laid in the principle of the formula. The formula can be used to determine the moisture-binding energy at the freezing of milk products.
\end{abstract}

Key words: sheep milk, freezing, cryoscopic temperature, moisture-binding energy.

A milk and milk products composition is a complex and multicomponent. A major component in the composition of these products is water. A degree of water-components interaction and its effect on organoleptic, thermodynamic, thermophysical, structural-mechanical and other properties of milk and milk products are determined not so much by the moisture content as by its thermodynamic state. One of the major thermodynamic characteristics representing a numeric side of the moisture binding in materials is the moisture-binding energy. Water in the milk and milk products is bound by other their

\footnotetext{
* To whom all correspondence should be addressed.
}

components of different binding energy, their quantitative relationship remains unclear. Meanwhile, many scientists consider in details qualitative assessment of each group, its characteristic, classification of the moisture binding ${ }^{1-10}$. Each form of the binding is characterized by its nature, formation conditions, energy, breakdown conditions and caused changes of the product.

In this aspect, a value of the moisturebinding energy for the phase change, i.e. for transition of water, containing in the product, into solid or gaseous aggregative state (freezing, drying), because these processes are connected with energy consumption, acquires a special meaning.

Analysis of works, studying the phase 
change process, shows that there is a difference between theoretically calculated energy and energy expended in practice for carrying out these processes. This difference is very considerable at analysis of food products' sublimation dehydration operating mode ${ }^{11-15}$. It can believed that this difference in experimental and calculated data is explained by the need to spend complementary energy for the bound moisture removal. In this connection, the matter about the moisture binding requires a detailed consideration. Moreover, there is no agreement of opinion by this matter.

At the present time, there are few researches, engaged by development of methods to determine the moisture-binding energy in the field of negative temperatures, characteristic for the sublimation dehydration of food products, including milk products ${ }^{16-19}$. By the moisturebinding energy determination method, they can be separated into 4 groups.

A basis of the first group of methods to determine the moisture-binding energy is an electrocalorimetric method, based on continuous automatic heat compensation, expended on the moisture evaporation (i.e. on change of water into vapor and breaking of the bond of water molecules with the material) at the drying at continuously changing its rate ${ }^{20-23}$.

However, the electrocalorimetric method for determination of the moisture-binding energy has important lack. An equilibrium distribution of an adsorbed substance by all grains of an adsorbent is hardly attained, sometimes is not attained at all in this method.

The second group of methods to determine the moisture-binding energy uses electrophysical methods, based on relationship of dielectric permeability, dielectric dissipation and specific conductivity on the moisture binding form in the product. In this method for determination of the moisture-binding energy, the studied product is placed between two electrodes, which at appropriate intervals measure specific conductance. Then, the conductance change kinetics' curve of the studied product from time is plotted. The curve has several knees and critical points, which pertain to different forms of the moisture binding with the product frame $\mathrm{e}^{18,24}$.

The third group of methods to determine the moisture-binding energy uses a method of nuclear magnetic resonance (NMR), based on recording of protons' mobility in a water molecule, contained in the product at low temperatures ${ }^{25,26}$. The NMR method allows precisely and quickly determine hydrogen atomic state in the water molecule. The most important characteristics at the research of moist food products by the NMR method are spin-lattice relaxation, described by time $\mathrm{O}_{1}$, and spin-spin relaxation, characterized by time $\mathrm{O}_{2}$ of nuclear spins, as they determine energy exchange with the environment by "lattice" and neighboring spins.

Currently, the NMR is the most valid measuring method of the bound moisture. It requires expensive equipment, trained staff and appropriate preparation to the experiment. The most important lack of the NMR method at the research of water condition and form of its binding in food products is that signals, obtained from the water protons, are distorted at the expense of signals of fat in the food products that results in degradation of accuracy of this method ${ }^{27-35}$. This fact provides limitation to use this method of determination the moisture binding in the food products.

The basis of the fourth group of methods to determine the moisture-binding energy in the food products is a method of drying thermographs, based on the laws of the drying kinetics, i.e. sequence of the moisture evaporation is determined by the intensity degree and binding with the product, that completely pertains to a scheme offered by P.A. Rehbinder ${ }^{16,36,37,38}$. The method of drying thermographs compares favorably from other methods by comparatively a small time and compactness, allowing simultaneously by results of one experiment determine all possible forms of the moisture binding in the product. However, this method has some lacks: analysis time at complex enough equipment, limitation of the studied products, need to dry only thin samples of the products. This not always gives possibility to provide uniformity of the drying product texture.

From the above reasoning, it may be concluded that in the field of temperatures below than the cryoscopic, characteristic for the work of vacuum-sublimation drying, it is reasonable to use the thermodynamic method for calculation of the moisture-binding energy in the products. This method explains "end" properties of water, because this method is based on classic laws of 
thermodynamics, which allow estimate the moisture-binding energy taking into account the product's properties.

Objective of the paper is to obtain a design equation for determination of the moisturebinding energy at the freezing of milk products below than the cryoscopic temperature, taking into account effect of frozen out, tightly bound moisture and total water content in the product.

To this end, using solutions' thermodynamics regularities, obtain an equation for calculation of the moisture-binding energy taking into account properties of the product and evaluate it at the freezing of the sheep milk.

\section{Materials and methods of the research}

Materials of the research are the sheep milk from farms of South Kazakhstan and Almaty oblasts.

The sheep milk initial humidity was determined by the standard drying method to the constant mass at temperature $105^{\circ} \mathrm{C}$ using a convectional drying box ShK-80 (Russia).

The initial humidity of the sheep milk from South Kazakhstan oblast consisted $\mathrm{W}_{\mathrm{i}}=84,44 \%$, and of the sheep milk from Almaty oblast consisted $\mathrm{W}_{\mathrm{i}}=83,45 \%$.

The frozen out moisture amount was determined experimentally, by data of the sheep milk freezing thermograph. To this end, the studied sample of the sheep milk was poured into a reservoir $(50 \mathrm{ml})$ and placed into a freezer $\left(\mathrm{t}_{\mathrm{a}}=-18^{\circ} \mathrm{C}\right)$ of "INDESIT" refrigerator and the freezing thermograph was taken. "Elitech" electronic sensor (Germany) was used as a temperature sensor.

Experimental values of $b$ coefficient, included into the equation (26) and taking into account availability of the bound water in the sheep milk, were determined by experimental data of the freezing thermograph: previously determining cryoscopic temperatures of the products and then by formula offered by G.B. Chizhov [2] the frozen out moisture amount was calculated. Then, the calculated values ù were arranged as point on a diagram in the form of dependence on ù. As the dependence $\omega$ on $\left(-\frac{1}{t}\right)$ is rectilinear, then the straight line is drawn through two points.

The water activity value $a_{\mathrm{w}}$ in the sheep milk was determined by “Aqualab” equipment $4 \mathrm{TE}$ model (Russia).

The water activity value was determined and then the moisture-binding energy experimental values were calculated by formula $\mathrm{L}=-\mathrm{R} \cdot \mathrm{T} \cdot \ln \cdot a_{\mathrm{w}}$ to compare the moisture-binding energy calculation results by the offered formula (26) with the experimental data.

\section{RESULTS AND DISCUSSION}

As different mineral and organic substances are solved in water contained in the milk products, then decrease of temperature is accompanied by appropriate change in a liquid solution concentration ${ }^{39}$.

At the freezing of milk products, which are complex multicomponent systems, the concentration change is more complex than at the freezing of a two-component solution. However, due to the gradual change of water into ice, while decrease of the temperature, a general increase regularity in the solution concentration is kept ${ }^{40-}$ 43.

In this connection, it is interesting to consider a numeric side of the moisture-binding energy in terms of the solutions' thermodynamics at negative temperatures.

In thermodynamics, a system balance, when entropy value reaches maximum and remains unchanged in time, is taken as a starting position

Table 1. Comparison.

\begin{tabular}{llllllll}
\hline \multirow{2}{*}{ Sheep milk } & & \multicolumn{6}{c}{ The moisture-binding energy value at the next temperature, kJ/kg } \\
\cline { 3 - 8 } & & -2 & -3 & -5 & -10 & -15 & -20 \\
\hline \multirow{2}{*}{ South Kazakhstan oblast } & Calculation & 1,045 & 2,093 & 4,202 & 9,543 & 14,986 & 20,536 \\
& Experiment & 0,986 & 3,413 & 4,795 & 9,996 & 14,828 & 20,163 \\
& Calculation & 0,968 & 1,819 & 4,221 & 10,050 & 15,662 & 21,083 \\
& Experiment & 0,878 & 1,884 & 3,770 & 10,128 & 16,585 & 21,661 \\
\hline
\end{tabular}


to compare analysis of different processes. If there are deviations from thermodynamic equilibrium state (in our case beginning of the freezing or sublimation), then the entropy inequality will occur. Let us assume that $\mathrm{Z}$ system drops from a definite initial state 1 with internal energy $U_{1}$ and entropy $\mathrm{S}_{1}$ into some final state 2 with internal energy $\mathrm{U}_{2}$ and entropy $\mathrm{S}_{2}$. In a result of the transition between two states 1 and 2, Z system, obtaining through the control surface a quantity of heat equal to $\mathrm{dQ}_{\dot{\mathrm{o}}}$ (this value depends on electric conductor type), changes its temperature $T_{1}$ to $T_{2}$ and performs an expansion work dW.

As $\mathrm{Z}$ system reacts on the environmental loads, i.e. on $\mathrm{dQ}_{\dot{\mathrm{O}}}$, this is open thermodynamic system. Usually, such system is considered completed with environment, where it functions, conventionally separating it from the rest system by adiabatic membrane, i.e. the control surface (Figure 1).

The open thermodynamic system entropy can be changed in a result of inside irreversible processes and exchange of material and energy with its environment.

In general, the open thermodynamic system entropy change can be written in the next form:

$$
d S_{s}=d S_{z}-d S_{e}
$$

If the process runs in conditions when the system is in enclosed volume and the environment serves only as a source for the heat input $d Q_{T}$ at the same temperature, then:

$$
d S_{\text {environment }}=\frac{d Q_{T}}{T}
$$

where $d Q_{\dot{D}}$ - heat, taken up by $Z$ system; $T$ - absolute temperature of the system.

Change of the system entropy taking into account the formula (2) is described by the next equation:

$$
d S_{c}=d S_{z}-\frac{d Q_{T}}{T}
$$

In this case, $d S_{s}$ characterizes uncompensated heat.

The next follows from the first law of thermodynamics:

where

$$
d Q_{T}=d U+p d V
$$

$d U$ - internal energy of the system;

$V$-volume.
(2), we obtain:

Putting the formula (4) in the equation

$d s_{C}=\frac{d U+\partial d V}{T}=\frac{T d S_{z}-d U-\partial d V}{T}$

The equation (5) can be simplified, as its numerator is equal to the value of Gibbs free energy, which is represented as:

$$
d F=d U+p d V-T d S_{z}
$$

(5), we obtain:

Putting the formula (6) in the equation

$$
T d S_{s}=-d F
$$

As is clear from the equation (7), the system state, i.e. $Z$ system's energy transformability degree (the entropy change) is determined by Gibbs free energy.

At constant temperatures and pressure of the system, a change of Gibbs free energy ÄF is determined by a change of transfer potential. Appropriate thermodynamic parameters, as temperature, pressure, concentration, density, etc. are selected as the transfer potential.

The system's thermodynamic parameter, defined by intensive properties, is selected considering the moisture transfer at the phase changes as the transfer potential. $\mu(\boxplus, O)$ chemical potential can be referred to such general parameters.

Then, taking into account the last, the next can be written:

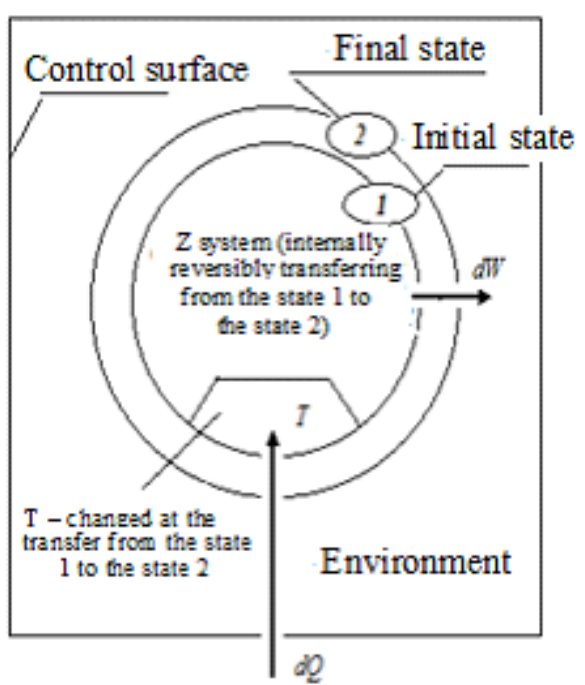

Fig. 1. The system description change diagram 


$$
d E=d U+p d U-T d S=d
$$

Joining (6) and (7), we obtain:

$$
T d S=-d F=-d
$$

Thus, in any irreversible mass exchange process, the energy transformability degree (the entropy formation), which is a function of the system state, is determined by Gibbs free energy or change of the chemical transfer potential.

The last formulation is very important for explanation of the moisture transfer mechanism in the freezing of food products and their next drying by sublimation.

In the freezing, the moisture transfer from

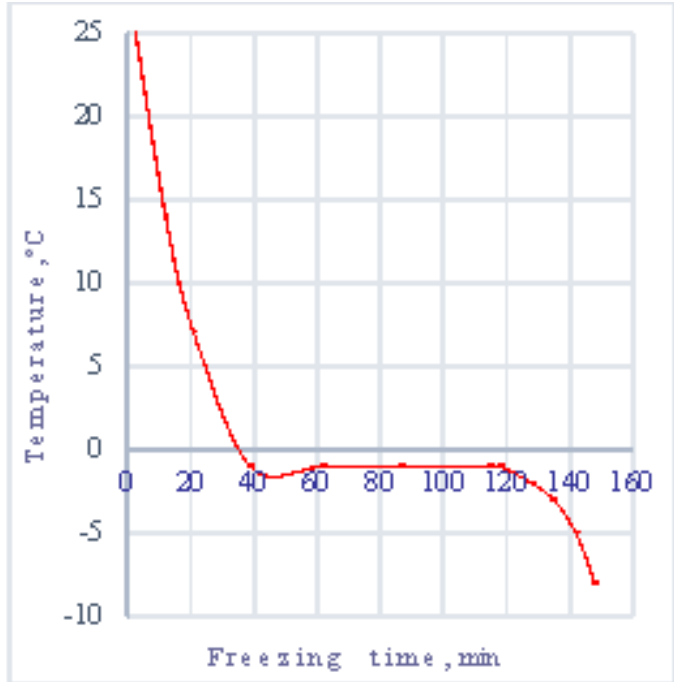

one phase to other results in a change of the moisture binding character and form with its solid frame. The moisture-binding energy numeric characteristic can be determined as a decrease of Gibbs free energy $\Delta F$ at $\dot{O}=$ const, expressed through $\Delta L$ work, which should be expended for separation of one mole from the material:

$$
\Delta F=\Delta L=R T \ln
$$

where $R$ - gas constant; $P_{n}$ - saturated vapor pressure above free water; $P_{i}$ - partial pressure of an equilibrium pressure above the product.

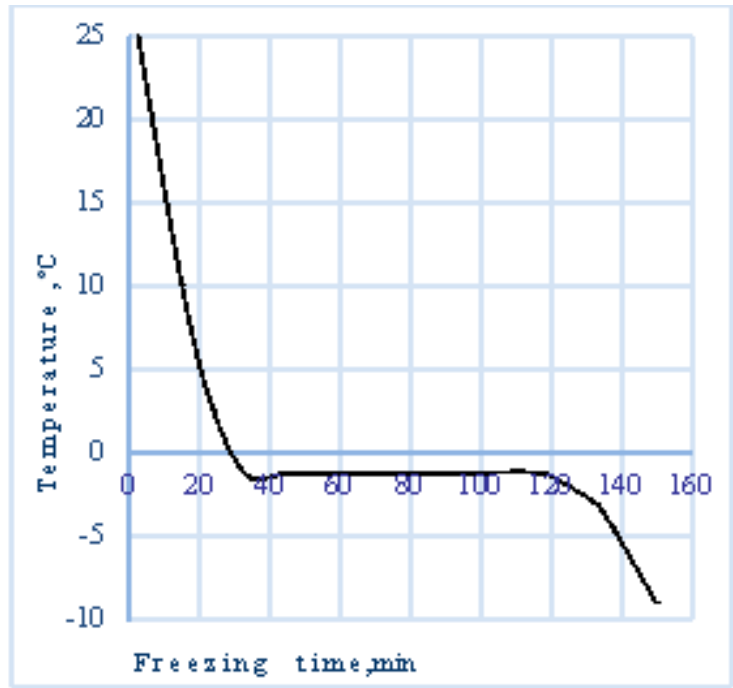

Fig. 1. The sheep milk freezing thermograph: a) South Kazakhstan oblast; b) Almaty oblast
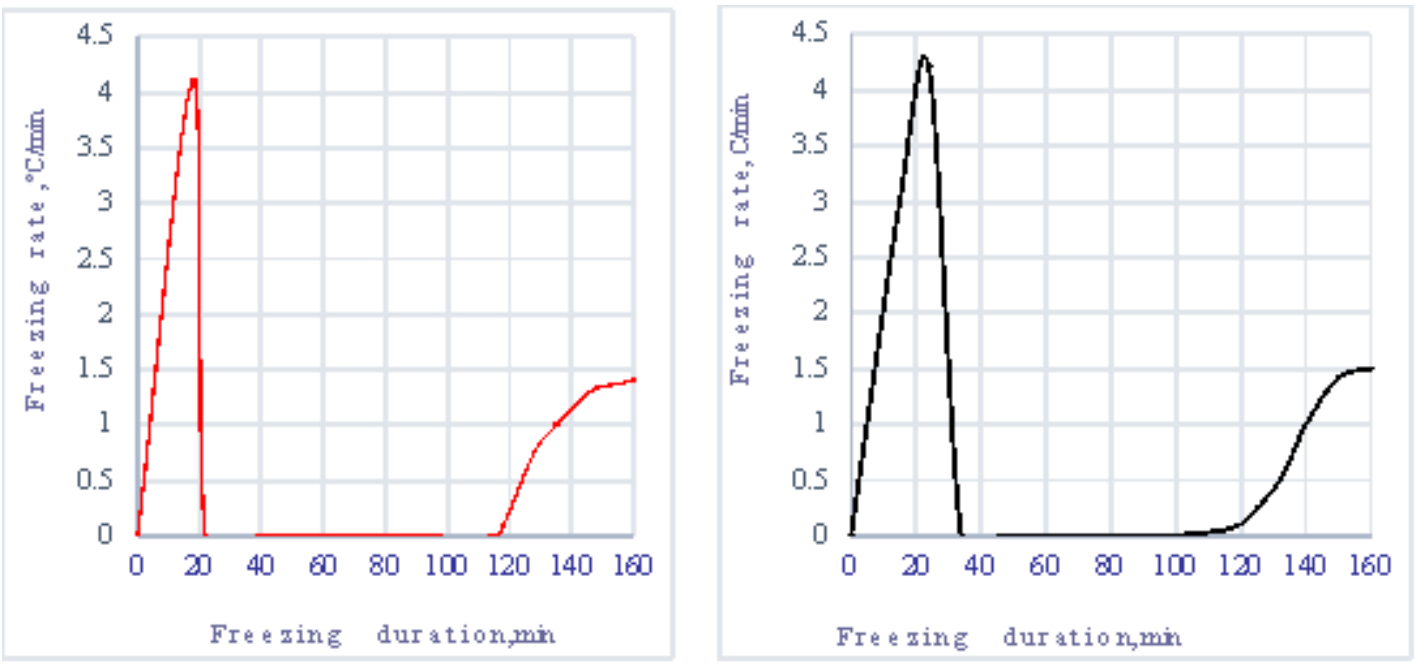

Fig. 2. The sheep milk freezing rate: a) South Kazakhstan oblast; b) Almaty oblast 
The milk and milk products are complex by their composition mixtures. Properties of such mixtures, their structure depend on interaction of all components. The basic structural component of the food products is water. Its content reaches $80 \%$ and more. As the research carried out by the NMR method shows, the water contained in the products can be separated into two types: free and bound.

The free moisture is not connected with adsorption forces and does not act as a solvent.

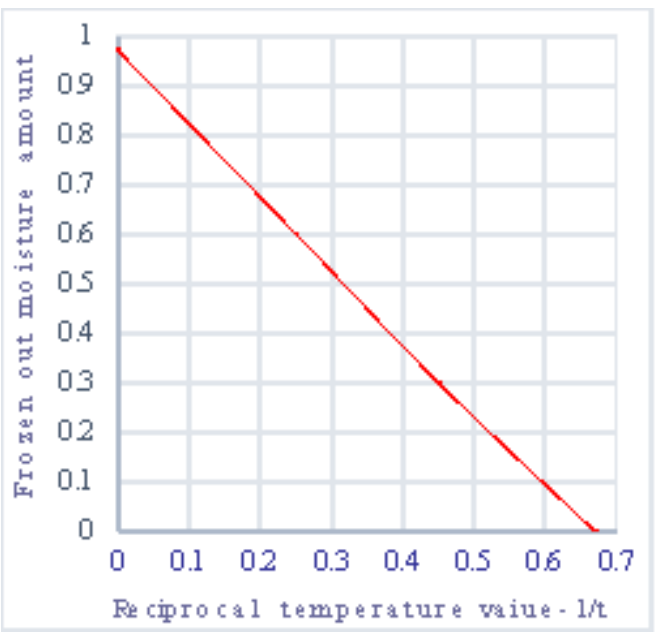

In accordance with this definition, unfrozen moisture in the product at temperature below the cryoscopic involves the bound water and a part of the free water, the solvent in the concentrated solution. At the decrease of temperature, the free moisture in the product passes into ice, i.e. "solution-ice" phase transition occurs.

The basic equation, characterizing phase transitions in the thermodynamics of solutions is Clapeyron-Clausius differential equation . According to this equation, a mechanical, heat

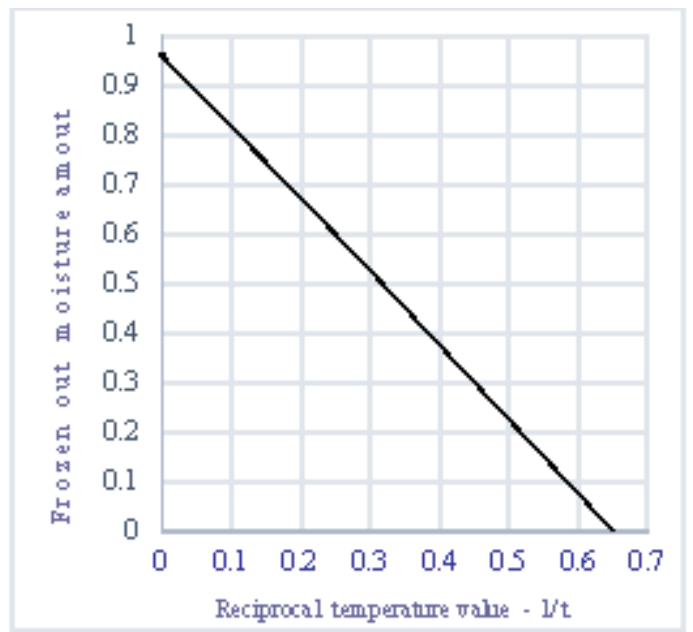

Fig. 3. Dependence of the frozen out moisture amount on the reciprocal temperature in the sheep milk from: a) South Kazakhstan oblast; b) Almaty oblast
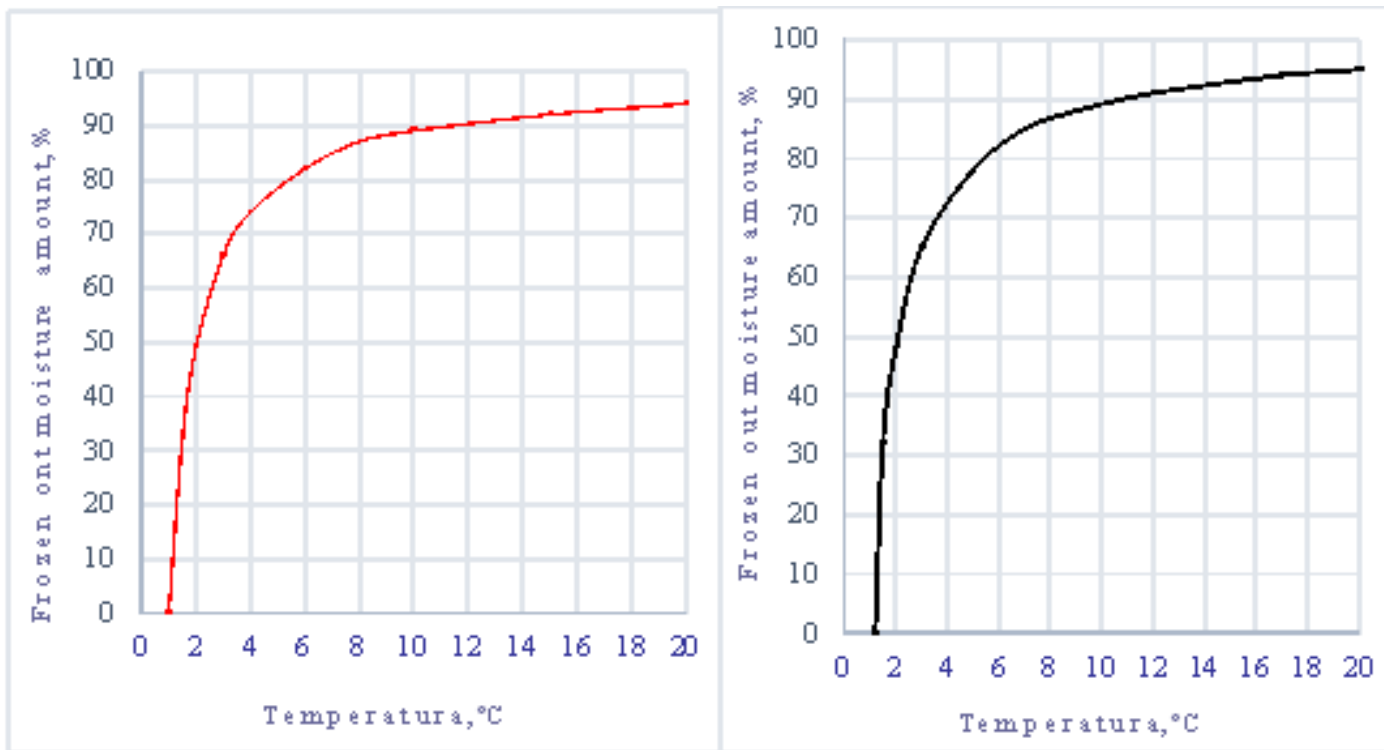

Fig. 4. Dependence of the frozen out moisture amount in the sheep milk on temperature: a) South Kazakhstan oblast milk; b) Almaty oblast milk 
condition and chemical potentials' equality should be observed at the phase boundary:

$T_{p}=T_{n}=T_{k}$

$P_{p}^{p}=P^{n}$

${ }_{\gamma}\left(\bigoplus_{\hat{e}}, \grave{O}_{\hat{e}}\right)+R \grave{O}_{\hat{e}} \cdot \ln \left(1-\dot{\zeta}_{\gamma}\right)={ }_{\ddot{e}}\left(\bigoplus_{\hat{e}}, \grave{O}_{\hat{e}}\right)+R \grave{O}_{\hat{e}} \cdot \ln$ $(1-\div)$

It is seen from the equation (13), that at the phase boundary, the chemical potentials $\mu_{\mathrm{p}}\left(\bigoplus_{\hat{e}}\right.$, $\left.\grave{O}_{\hat{e}}\right)$ and ${ }_{\ddot{e}}\left(\bigoplus_{\hat{e}}, \grave{O}_{\hat{e}}\right)$ are expressed in a hidden view. The clear expression $(\bigoplus, O)$ can be obtained by the differential equation (13):

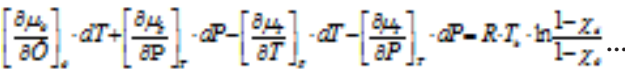

Using known in the thermodynamics ratios:

$$
\begin{aligned}
& {\left[\frac{\partial \mu_{p}}{\partial T}\right]_{p}=-S\left[\frac{\partial \mu_{T}}{\partial T}\right]_{p}=-S\left[\frac{\partial \mu_{p}}{\partial P}\right]_{T}=V_{p}} \\
& {\left[\frac{\partial \mu_{T}}{\partial \mathrm{P}}\right]_{T}=V_{\pi}}
\end{aligned}
$$

$\mathrm{r}_{\mathrm{o}}=\mathrm{T}_{\hat{\mathrm{e}}} \cdot\left(\mathrm{S}_{\gamma}-\mathrm{S}_{\ddot{\mathrm{e}}}\right)$

Where:

$$
-\frac{\mathrm{r}_{0}}{T} \cdot d T+\left(V_{p}-V_{\ddot{e}}\right) \cdot d P=R \cdot T_{k} \cdot \ln \frac{1-\chi_{\ddot{e}}}{1-\chi_{\partial}} \ldots
$$

Substituting ln function by its first expansion term in Taylor series, i.e.

$\ln (1-)-\ln (1-)=--(-)=-=$

Then, the expression (16) has the next form:

$$
\frac{\mathrm{r}_{0}}{T} \cdot d T+\left(V_{p}-V_{\Omega}\right) \cdot d P=R \cdot T \cdot d \chi \ldots
$$

Physical properties of the water molecules at the boundary surface and their effect on the balance were not considered at derivation of the equation (18). In the surface phase layer by thickness in the order of the molecular interaction radius $(1 \mathrm{~nm})$, the molecules interact not only with the molecules of their phase, but with the other phase neighboring layer. Therefore, physical properties of the water molecules differ from properties of molecules inside (in the volume) the phase.

As is known from the laws of surface phenomenon thermodynamics, increase in the system surface at Ò = const is accompanied by energy consumption. Thus, to form a new surface, some particles from the volume should transit to the surface, that is connected with energy against molecular forces.

The energy transfer chemical potential of the loosely bound moisture is determined by the next equation:

$\mu_{\partial}-\mu_{\ddot{e}}=\Delta \mu=-\frac{2 \delta}{\rho} \cdot \frac{1}{r}$

where $\rho$ - ice density;

$r$ - ice crystal curvature radius;

$\delta$ - surface tension at "solution-ice" phase boundary.

Taking into account the equation (19), a differential of the system's free energy, which consists of the solution and ice, when $T=$ const, $P$ $=$ const, and the chemical potential in the phases is equal, has the next form:

$$
\Delta F=-\frac{{ }^{\mathrm{r}} \mathrm{o}}{T} \cdot d T+\Delta V \cdot d P-R \cdot T \cdot d \chi-\frac{2 \cdot \delta}{\rho} \cdot d\left(\frac{1}{r}\right) \ldots
$$
therefore:

At the system equilibrium $d F=0$,

$$
\frac{2 \cdot \delta}{\rho} \cdot d\left(\frac{1}{r}\right)=-\frac{\mathrm{r}_{\mathrm{o}}}{T} \cdot d T+\Delta V \cdot d P-R \cdot T \cdot d \chi
$$

If define, that $\Delta V=R T / P$, then after integrating the equation (21) at $O=$ const, we obtain:

$$
\frac{2 \delta}{\rho \cdot r}=R T \ln \frac{P_{p}}{P_{\pi}}-R T \Delta \chi
$$

Analogously, integrating the equation (21) at $P=$ const, we obtain:

$$
\frac{2 \cdot \delta}{\rho \cdot r}=-r_{o} \cdot \ln \frac{T}{T_{k}}-R \cdot T \cdot \Delta \chi
$$

Making equal (22) and (23), we obtain a formula to determine the moisture-binding energy at negative temperatures:

$L=R T \ln \frac{P_{p}}{P_{x}}=-r_{o} \ln \frac{T}{T_{z}}$ 
where $r_{o}$ - "water-ice” phase transiton heat; $T_{k}$ - cryoscopic temperature of the solution.

From this expression it is not too difficult to note that the obtained value $r_{0} \ln$ is energy, expended for separation of one kilogram of the bound water from ice.

As the milk products' cryoscopic temperature, included into the equation (24), depends on concentration of solved mineral and organic substances and connected with thermodynamic indicator of the frozen out water amount (ù), tightly bound moisture (b) and its total content in the product $(W)$ by the next equation :

$$
\omega=\left(1-b \frac{1-W}{W}\right)\left(1-\frac{T_{k p}-273}{T-273}\right)
$$

Taking into account the expression (25) after simple mathematical transformations, we obtain an expression, which connects a value of the binding energy with amount of the frozen out, bound moisture and its total content in the product:

$$
\mathrm{L}=-\mathrm{r}_{\hat{i}} \cdot \ln
$$

where $u$-specific humidity of the product, $b$ - coefficient, taking into account the tightly bound moisture.

Thus, the obtained equation (26) is the calculating formula to determine the moisturebinding energy in the milk products at temperatures below the cryoscopic.

To compare the moisture-binding energy value, obtained by the formula (26) with experimental data, it is necessary to possess by data on the frozen out moisture amount ù and $b$ coefficient, taking into account the tightly bound moisture in the milk products.

Analysis of scientific-technical literature shows that there is no data on the amount of frozen out moisture and coefficient, taking into account the tightly bound moisture in the sheep milk. Therefore, to determine their values it is necessary to carry out experimental research.

\section{Research results}

To use the offered equation (26) in practice, the regularities to change the frozen out moisture amount ù on the product freezing temperature and $b$ coefficient, taking into account the tightly bound moisture in the milk products should be established. In this connection, the first stage of the research establishes the regularities to change the parameter ù from temperature and $b$ coefficient value for the sheep milk experimental samples. Then, using their values, the moisturebinding energy values at their freezing are calculated.

Determination of ù values and $b$ coefficient included into the equation

To determine the values ù and coefficient $\boldsymbol{b}$, it is necessary experimentally find the cryoscopic temperature values for the sheep milk. To this end, let's take the sheep milk pilot samples freezing thermograph.

The sheep milk freezing thermograph research results are given on Figure 1.

Analysis of the sheep milk freezing thermograph shows that there are 3 segments differing by a slope of line during the sheep milk freezing. In the beginning, there is cooling and subcooling during 36-40 minutes (I segment), then a long-lasting isothermal ground (from 36 minutes to 120 minutes), which ordinate corresponds to the cryoscopic temperature (II segment). Then temperature in the sheep milk begins to decrease, at that the temperature decrease rate increases, this means completion of the freezing phase, which duration consists 32-36 minutes (III segment). For more detailed phase transition analysis of the sheep milk moisture, the freezing thermographs were differentiated by time, obtaining dependence of the research objects' freezing rate on the time. The research results are shown on Figure 2.

As is clear from Figure 2, there is a segment with zero freezing rate, corresponding to the isothermal ground of the moisture crystallization beginning in the sheep milk. Besides, analysis of the freezing rate diagram can determine the completion point of the tightly bound moisture crystallization: it corresponds to the knee point at the freezing rate curve.

From the presented freezing thermograph and freezing rate diagram, it may be concluded that the crystallization completion point corresponds to the temperature of the sheep milk from South Kazakhstan oblast in $-1.1^{\circ} \mathrm{C}$, and of the sheep milk from Almaty oblast in $-1.2^{\circ} \mathrm{C}$. Besides, these figures shown that the cryoscopic temperature of the sheep milk from South Kazakhstan oblast differs from the cryoscopic temperature of the sheep milk from Almaty oblast. This difference is explained by the sheep milk moisture's chemical composition and 
binding form.

The sheep milk cryoscopic temperature determined experimental values allowed calculate $b$ coefficients values and $\omega$ frozen out moisture amount, included into the equation (26). The calculation results are given on Figures 3 and 4 .

As Figure 3 shows, on Y-axis equal to 0 , the line cuts an interval equal to 0.97 for the sheep milk from South Kazakhstan oblast, to 0.96 for the sheep milk from Almaty oblast. From this equality, we find $\mathrm{b}$ value, as the water content $\mathrm{W}$ in the studied products is known. $\mathrm{u}=0.98$ was obtained from the diagram, where $b=0.0752$ for the sheep milk from South Kazakhstan oblast, and ù $=0.97$ was obtained from the diagram, where $b=0.0805$ for the sheep milk from Almaty oblast.

Analysis of data given on Figure 3 shows that in the interval of temperatures from the cryoscopic to $-20^{\circ} \mathrm{C}$, different moisture binding forms such as loosely bound moisture (low lines) and tightly bound moisture (upper lines) have place in the studied sheep milk samples. Only loosely bound moisture can freeze in the considered temperature interval in the studied sheep milk samples.

The research results of the frozen out moisture dependence on temperature are shown on Figure 4.

It is seen from Figure 4 that increase in the frozen out moisture amount is very fast at the beginning, and then it is sharply reduced. The transition dynamics of the loosely bound moisture into ice in the studied sheep milk samples has the next regularities. In the interval from the cryoscopic temperature to $-10^{\circ} \mathrm{C}$, the frozen out moisture amount in the sheep milk from South Kazakhstan oblast increases from $0 \%$ to $87 \%$, and in the sheep milk from Almaty oblast increases from $0 \%$ to $88 \%$.

At the further decrease of the freezing temperature from $-10^{\circ} \mathrm{C}$ to $-20^{\circ} \mathrm{C}$ and below, there is a smooth and graded transition of the rest loosely bound moisture to ice. The established regularity is characteristic for all kinds of the studied sheep milk samples. Increase in the frozen out moisture amount at the decrease of temperature from $-10^{\circ} \mathrm{C}$ to $-20^{\circ} \mathrm{C}$ consists $4 \%$ for the sheep milk from South Kazakhstan oblast and 3.95\% for the sheep milk from Almaty oblast.

Analysis of data given on Figure 4 also shows that with the decrease of temperature there is decrease of the bound water fraction. This is explained by the fact that the sheep milk contains low-molecular substances solutions (lactose, salts of organic and inorganic acids and other substances), which have definite osmotic pressure (depending on the specified substances' mass fraction). Occurring osmotic forces separate the bound water molecule and transit it into a solution, from which it gradually freezes out, as the equilibrium concentration, corresponding to the definite temperature, should be kept. The osmotic forces operation on the separation of $1 \mathrm{~kg}$ of the bound water at the definite temperature is equal to its binding energy at the same temperature.

Thus, based on the given data, it may be concluded that the basic moisture part in the sheep milk is frozen in the interval of temperatures up to $-10^{\circ} \mathrm{C}$. This should be taken into account at the selection of bottom sublimation temperature at their sublimation drying.

\section{Determination of the moisture-binding energy} values in the sheep milk

Using $\omega$ experimental values and $b$ coefficient, by the equation (26), the moisturebinding energy values in the sheep milk samples at their freezing in the interval of temperatures from the cryoscopic to $-20^{\circ} \mathrm{C}$ were calculated. The obtained results were compared with the experimental data on the freezing of the samples at the same interval. The comparison results are given in Table 1.

Analysis of data from Table 1 shows that at the sheep milk freezing, the moisture-binding energy change regularity on the temperature has linear character. With decrease of the temperature, the moisture-binding energy value steadily increases. For example, in the interval of temperatures from the cryoscopic to $-10^{\circ} \mathrm{C}$, the moisture-binding energy value in the sheep milk from South Kazakhstan oblast reaches $9.543 \mathrm{\kappa J} /$ $\mathrm{kg}$, and in the sheep milk from Almaty oblast reaches $10.052 \mathrm{KJ} / \mathrm{kg}$. In the interval of temperatures from $10^{\circ} \mathrm{C}$ to $-20^{\circ} \mathrm{C}$, the moisture-binding energy values in the sheep milk from South Kazakhstan oblast increase in 2.15 times, and at the end of the temperature range reach $20.536 \mathrm{e} J / \mathrm{kg}$. And, in the sheep milk from Almaty oblast this indicator increases in 2.10 times, and its values at temperature in $-20^{\circ} \mathrm{C}$ reach $21.083 \mathrm{KJ} / \mathrm{kg}$.

Comparative analysis of data from the 
Table for the sheep milk binding energies, determined by the experimental and calculation methods shows that their comparison is no more than $2.7 \%$. Based on the data analysis, we may state about justification of provisions, laid in the basis at the derivation of the moisture-binding energy equation.

\section{CONCLUSION}

Based on the carried out research, it may be concluded that beginning of the sheep milk's water-ice phase transition, i.e. the cryoscopic temperature for the sheep milk from South Kazakhstan oblast is $-1.1^{\circ} \mathrm{C}$, and for the sheep milk from Almaty oblast is $-1.2^{\circ} \mathrm{C}$.

The research proved that in the interval from the cryoscopic temperature to $-10^{\circ} \mathrm{C}$, the frozen out moisture amount in the sheep milk from South Kazakhstan oblast increases from $0 \%$ to $87 \%$, and in the sheep milk from Almaty oblast increases from $0 \%$ to $88 \%$. At the further decrease of the freezing temperature from $-10^{\circ} \mathrm{C}$ to $-20^{\circ} \mathrm{C}$ and below, there is a smooth and graded transition of the rest loosely bound moisture to ice. Based on the obtained data, we may maintain that the basic moisture part in the sheep milk freezes in the interval of temperatures to $-10^{\circ} \mathrm{C}$.

The research results shows that $\boldsymbol{b}$ coefficient value, considering tightly bound moisture in the sheep milk from South Kazakhstan oblast is $b=0.0752$, and in the sheep milk from Almaty oblast it is $b=0.0805$.

The research established that in the interval of temperatures from the cryoscopic to $20^{\circ} \mathrm{C}$, the moisture-binding energy change regularity has linear character.

Comparison of numeric values between theoretically calculated moisture-binding energy and experimental data at the freezing of the sheep milk samples shows that the difference is no more than $2.7 \%$. This proves justification of conditions laid in the principle of the formula. The formula can be used to determine the moisture-binding energy at the freezing of milk products.

\section{REFERENCES}

1. Shingisov A.U. Research the rotation quantities of water to ice in koumiss and shubat/ Zharshy-
2008. - 1 4. - pp. 58-59.

2. Ginzburg A.S., Savin I.M. Mass transfer characteristics of foods. M .: Light and food industries. - 1982. - $280 \mathrm{p}$.

3. Kaivarainen A.I. The dynamic behavior of proteins in an aqueous medium and its functions. L .: Nauka, 1980. - 272 p.

4. Ismailova V.N., Yampol'skaya G.P., Summ B.D. Surface phenomen in protein systems. - M .: Chemistry, 1988. - 272 p.

5. Adambounow T.L., Gastaigne F., Dillon I.C. Abaissement de'l activiti de'l egumes tropicouen par deshydration osmotigue partielle // Science alimentaria. 1983. v. 3. ${ }^{1}$ 4. pp. 551-567.

6. Cauril M. Raoult's law water activity and moisture availability in solution // Journal of Food Science. 1983. v. 48. - pp. 648-649.

7. Chirife J., Fontan CF Water activity of Fresh Foods // Journal of Food Science. 1983. v. 47. pp. 661-663.

8. Chirife Jorge, Buera Maria De Pilar. Water activity, glass transition and microbial stability in concentrated / semi moist food systems // Journal of Food Science. - 1999. v. 59. ${ }^{1}$ 5. - pp. 921-927.

9. Muller J.G. Freeze Concentration of Food Liquids: Theory, Practice and Economic. «Food Technology», vol. 21, 1967, pp. 49-58.

10. Kamovnikov B., Semyonov G., Kushnerova G., Yausheva E. Factors of raw material preparation securing maximum production of food products of freeze drying // International institute of refrigeration, Italy (Bressanone), 1974. - 8 p.

11. Hartman G.J., Scheide J.D., Ho Chi - Tang. Effect of water activity on the maijor volatiles produced on a system approximating cooked meat // Journal of Food Science. - 1984. v. 49. ${ }^{1}$ 2. - pp. 607- 613.

12. Ginzburg A.S. Fundamentals of the theory and technique of drying foods. - M .: Food Industry, 1973. - 528 p.

13. Guygo E.I., Zhuravskaya N.K., Kauhcheshvili E.I. Freeze drying in the food industry. - M .: Food Industry, 1972. - 433 p.

14. Kamerbaev A.J. The role of water in food products and its function. - Almaty. - 2001. 203 p.

15. Olenev Y.A. Energy outage moisture during the hardening ice cream. // Refrigeration technics.1983. - ${ }^{1}$ 5. - pp. 41-42.

16. Shingisov A.U., Chomanov U.Ch. Determination of the heat of vaporization of dairy products in the freeze-dried // Research and results (KazNAU). Almaty. ${ }^{1}$ 4. - pp. 59-61.

17. Rey L. L'humidite residuelle des produits lyophilises Herman. Paris, 1964. 
18. Kamovnikov B.P., Malkov L.S., Voskoboynikov V.A. Vacuum freeze-drying of foods. M .: Agropromizdat, 1985.-285 p.

19. Lorentzen J. Industrial freeze drying plants for foods // In Freeze Drying and Advanced Food Technology: Academic Press, London, 1975.

20. Shingisov A.U. šoyulandyryl“an $s^{-} t>y s h>y l d y$ én $^{3}$ mderd ${ }^{3}$ vacuum sublimatsiyaly> kept ${ }^{3} \mathrm{ru}$ Ùd $^{3} s^{3}$ ndeg $^{3}$ Zhylu shy“ynyn anystau // Bulletin Innovation Evraziskogo University. Pavlodar 2008-1 4- pp. 32-33.

21. Bahrami M., Culham J. R., Yovanovich M. M. A scale analysis approach to thermal contact resistance // ASME J. of Heat Transfer, 2004, Vol. 126, No. 6; pp. 896-905.

22. Harper J.C., Tappel A.L. Freeze-Drying of Food Products // Advances in Food Research :: Academic Press. Vol. 7, 1957. - pp. 171-234.

23. Kazan V.M. Analysis of the forms of communication and the state of the moisture absorbed by the particulate body by kinetic drying at-O. - DAN SSSR, 1960. t. 130. - ${ }^{1}$ 5. pp. 132-134.

24. Karel M. - Applied Science publischers LTD. London, 1978.

25. Duckworth R.B. - J. Food Technol., 1971, 6 p.

26. Kulagin V.N., Rogov I.A., Kurban A.B. A study of the phase transition of water in frozen muscle tissue by NMR. // Refrigeration tehnika.- 1982. - 1 5. - pp. 42-44.

27. Slichter C., "Principles of Magnetic Resonance," Springer, New York, 1990, 655 p.

28. Dybowski C. and R.L. Lichter, "NMR Spectroscopic Techniques,” Dekker, New York, 1987, 373 p.

29. Kamerbaev A.J. Thermodynamic fundamentals of hydration and drying of multicomponent food systems: Cand ... dis. Doc. tehn. Sciences. Semipalatinsk, 2002.- 35 p.

30. Water and aqueous solutions at temperatures below $0^{\circ} \mathrm{C} /$ Translated from English. Ed.
F.Franksa. - Kiev, Science Thought. - 1985. 387 p.

31. Kirillin V.A. Thermodynamics of solutions. - M .: Energia, 1980 - 288 p.

32. King C.J. Application of freeze drying to food products // In Freeze Drying and Advanced Food $\therefore$ Academic Press, London, 1975.

33. Gunther H., "NMR Spectroscopy - An Introduction,” John Wiley, 1980. (QD96 / N8 / G8313)

34. Becker E.D., "High Resolution NMR. Theory and Chemical Applications,” Academic Press, 2nd Ed., 1980. (QD96 / N8 / B43)

35. Levy G.C., Ed., "NMR Spectroscopy: New Methods and Applications,” ACS, 1982. (QD96 / N8 /)

36. Shanbhad S, Steinberg M.P. Nel. Son. A.J. - J. Food Science, 1970, 35 p.

37. Kriescher O. Scientific bases drying technology. - M .: IL. 1961. 540 p.

38. Dyer J.R., "Applications of Absorption Spectroscopy to Organic Compounds," Prentice-Hall, 1965. (QD476 / D91.2)

39. Water in food / Under. Ed. RB Dokuort. Translation from English .. - M .: Food Industry, 1980. - 286 p.

40. Thermodynamics Research Center Data Project, "Selected Nuclear Magnetic Resonance Spectral Data 1960-1968,” Texas A \& M University, 1968. Ref. QD591 / + M3

41. Humble Oil and Refining Co., "A Catalog of the Nuclear Magnetic Resonance Spectra of Hydrogen in Hydrocarbons and Their Derivatives,” Baytown, Texas. Ref. QC7631 / + H8

42. Yukawa Y., "Handbook of Organic Structural Analysis,” WA Benjamin, Inc., 1965. Ref. QD291 / Y8

43. Bovey F.A., "Nuclear Magnetic Resonance Data Tables for Organic Compounds,” Vol. I, Interscience Publishers, Inc., New York, 1967. Ref. QC / 762 / + B6 